\title{
Rectal Anastomotic Leak, CTCAE
}

National Cancer Institute

\section{Source}

National Cancer Institute. Rectal Anastomotic Leak, CT CAE. NCI Thesaurus. Code

C143801.

A finding of leakage due to breakdown of a rectal anastomosis (surgical connection of two separate anatomic structures). 